\title{
REJOINDER TO ARTICLE BY HAROLD M SHRODER: THE FALLACY OF USING IN-BASKET BASED MEASURES FOR THE VALIDATION OF LEADERSHIP DIMENSIONS
}

\author{
HH SPANGENBERG \\ Centre for Leadership Studies, Graduate School of Business \\ University of Stellenbosch \\ CC THERON \\ ccth@sun.ac.za \\ Department of Industrial Psychology \\ University of Stellenbosch
}

\begin{abstract}
A response is given to the critical questions and concerns raised by Schroder (2004) on the validation study by Spangenberg and Theron (2003). The importance of open debate as an expression of scientific rationally in service of the epistemic ideal of science is acknowledged. Schroder's (2004) concern essentially centers on the use of the inbasket as a stand-alone measure and the appropriateness of the design of the Spangenberg and Theron (2003) study for the investigation of the validity of the HPLC's. The objectives of the Spangenberg and Theron (2003) study are re-examined. The prudence of using and validating the in-basket as a stand-alone measure is discussed.
\end{abstract}

\section{OPSOMMING}

Repliek word gelewer op die kritise vrae en besorgdhede wat deur Schroder (2004) geopper word oor die validasiestudie van Spangenberg en Theron (2003). Die belang van 'n oop gesprek as manifestasie van die rasionaliteit van wetenskap in diens van die epistemiese ideal word erken. Schroder (2004) se kommer sentreer wesenlik rondom die gebruik van die posmandjie as ' $n$ meetinstrument in eie reg en die toepaslikheid van die ontwerp van die Spangenberg en Theron (2003) studie vir die validasie van die HPLC's. Die doelstellings van die Spangenberg en Theron (2003) studie word weer in oënskou geneem. Die wysheid om die posmandjie as 'n meetinstrument in eie reg te gebruik en te valideer word bespreek.

The objectives of Industrial Psychology are fourfold, namely:

1. To formulate credible and valid psychological explanations of the behaviour of people at work; and (flowing from that);

2. Demonstratively affect efficient and equitable improvement in the behaviour/performance of people at work through;

3. An integrated set of HR functions aligned with HR strategy, which in turn is;

4. Derived from and aligned with an appropriate business strategy. The first objective, i.e. to explain work behaviour in terms of a nomological network, is derived from the last three objectives.

Knowledge provides the power and ability to improve the less than perfect status quo. Knowledge on working man's behaviour is sought to improve organizational effectiveness by affecting employee performance through theory based human resource management interventions. The mission of Industrial Psychology is, however, not fully explicated through a description of what the discipline tries to achieve. It also requires a description of the method through which the objectives are to be achieved. The majority of I/O psychologists believe that industrial psychology's ideal of valid and credible psychological explanations of the behaviour of working people can be best achieved through the scientific method. This is based on industrial psychology's control mechanisms of objectivity and rationality that are designed to compensate for the fallibility of human decision-making. The scientific method is objective to the extent to which it succeeds in reducing error which threatens the validity of inferences (Babbie \& Mouton, 2001). The scientific method is rational to the extent to which it allows for the evaluation of the evidence on which scientific verdicts are based. Scientific rationality serves the epistemic ideal by submitting new scientific claims, and the theoretical and methodological argument on which it is based, to the scrutiny of suitably qualified members of the scientific community. Industrial Psychology is therefore in the long run more likely to arrive at close approximations of the truth if it places a high value on theoretical and methodological arguments being honestly revealed, peer reviewed and openly debated. Given that

Requests for copies should be addressed to: CC Theron, Department of Industrial Psychology, University of Stellenbosch, Private Bag X1, Matieland, 7602 scientific rationality serves the epistemic ideal of science, the critical questions and concerns raised by Schroder (2004) on the validation study by Spangenberg and Theron (2003) should be welcomed as an opportunity to critically reevaluate the theoretical and methodological grounds on which the conclusions reached by Spangenberg et al. (2003) are based.

Schroder's $(2004$, p. 1) main criticism seems to be aimed at the use of the in-basket as a stand alone measure to validate the High Performance Leadership Competencies:

The in-basket cannot be used as a complete measure of leadership and therefore cannot be used alone as the basis for investigating the validity of the HPLCs.

In addition Schroder (2004, p. 2) remarks:

... The design of the Spangenberg/Theron study was inappropriate for investigating the validity of the HPLCs and the title itself is inappropriate and misleading. More accurately it was a study of the validity of in-basket based measures of leadership dimensions.

Schroder (2004) is quite correct in objecting to the appropriateness of the title of the Spangenberg and Theron (2003) article. In addition he could have criticized the numerous other references made in Spangenberg and Theron (2003) to the validation of the High Performance Leadership Competencies.

In its most general sense validity should be interpreted as the extent to which inferences are warranted or permissible (Guion, 2002). Measurement validity thus refers to the extent to which the inferences made from test scores or the interpretation [i.e. meaning] assigned to test scores is justified/supported (Guion, 2002). Strictly speaking, therefore, what is being validated is not the measuring instrument, nor the measures obtained from the instrument, but rather the inferences made from the measures. Messick (1989, p. 13), in his monumental and definitive treatment of the validity concept, states:

Validity is an integrated evaluative judgment of the degree to which empirical evidence and theoretical rationales support 
the adequacy and appropriateness of inferences and actions based on test scores or other modes of assessment. ... Broadly speaking, then, validity is an inductive summary of both the existing evidence for and the potential consequences of score interpretation and use. Hence what is to be validated is not the device as such but the inferences derived from test scores or other indicators - inferences about score meaning or interpretation, and about the implications for action that the interpretation entails.

It thus clearly is inappropriate to speak of the validation of HPLCs. Despite the title and the numerous other unfortunate occurrences of this phrase in their article, this, however, never really was the intent of Spangenberg and Theron (2003). The High Performance Leadership Competencies (HPLCs) (Schroder, 1989) have been used by various South African organisations since 1997 for strategic planning and the assessment and development of senior and executive management. Typically the HPLCs are assessed by means of multiple measures obtained from several different exercises comprising an assessment centre. The University of Stellenbosch Business School (USB) has recently initiated research on the leadership patterns of MBA students. Specifically the hypothesis is being explored that the MBA program could induce improvement in the competency profile of MBA students. Since the use of an assessment centre for research purposes is expensive and time consuming, it was decided to measure the HPLCs by means of an in-basket, a key exercise of the assessment centre. Schroder was commissioned to develop such an exercise specifically for the USB and specifically for this purpose. In his commentary on the Spangenberg and Theron (2003) article, Schroder affirms the meaningfulness of the use of an in-basket for this purpose by stating:

(The in-basket) provides an efficient and effective vehicle to offer "hands-on" experience for leadership development programmes. Feedback on dimensions of leadership measured by non-interactive methods like the in-basket can be used to demonstrate the dimensions and as a basis for coaching. They can be used on a pre-post basis to plot developmental progress in non-interactive aspects of leadership which will build the readiness of participants to transfer this to the broader job of leading.

Given the implicit, if not explicit, objective of the MBA programme to affect improvement in managerial performance it, however, only makes sense to use the USB in-basket to provide feedback, to coach and to plot developmental progress as part of the MBA programme, if level of managerial performance is systematically related to in-basket performance. To aspire to affect improvement in the HPLC profile as measured by the USB in-basket, and to use the USB in-basket for feedback and coaching to assist in achieving such improvement without any evidence that the in-basket derived profile is systematically related to managerial performance seems questionable both ethically and practically. To paraphrase Schroder $(2004$, p. 1), one could have expected the architect of the USB intervention to have selected the most valid measure of the Schroder leadership dimensions to assist in the leadership development of MBA students.

The real objective of the Spangenberg and Theron (2003) study consequently was to examine whether the level of managerial performance may permissibly be inferred from the measures derived from the USB in-basket due to a systematic relationship between the scores on the in-basket and construct valid measures of managerial performance. Managers are responsible, and should be held accountable for the performance of their work units (Henning, Spangenberg \& Theron, 2003). Viewed from a competency model perspective (SHL, 2000), the High Performance Leadership Competencies are behavioural expressions of a complex nomological network of person- centered dispositions and attainments (meant to be affected by MBA study) which result in superior unit performance, especially in a complex and dynamic environment. Despite the inappropriate wording of the title and the numerous other unfortunate references to HPLC validation in their article, Spangenberg and Theron (2003, p. 29) nonetheless managed to provide the following more accurate formulation of their research objective.

The purpose of the current study was to examine the validity of unit performance related inferences made from the HPLCs as measured by the USB in-basket.

We would agree with Schroder (2004) that to obtain a comprehensive measure of leadership competence would require multi-dimensional observations of managers in a broad range of situations across several different exercises which simulate the breadth of a leader's work. The in-basket should form part of array of assessment techniques to describe the HPLCs of managers. Again Schroder (2004, p.2) seems to concur:

So does the in-basket have a place in management development and research? Indeed, it does. While it is inappropriate to use it alone when more accurate measures of leadership are demanded in research and assessment, these measures (1) are needed to round out our picture of leadership based on multiple exercises

However, it only seems prudent to combine in-basket information with information obtained from other assessment techniques if (a) the in-basket information is relevant to the inference being made, and (b) it does not duplicate the information rendered by the other information sources. In the context of managerial selection and/or managerial development the use of the in-basket alongside an array of other assessment techniques thus seems questionable if it fails to significantly explain (unique) variance in managerial (outcome) performance.

Despite their rather disappointing findings, Spangenberg and Theron (2003, p. 37) remain optimistic about the usefulness of the in-basket in managerial selection and development, also with regards to the assessment of the HPLCs.

In the South African context a major intervention will be needed to ensure effective and fair application of the inbasket as a single exercise. It should probably start with the sensitisation of practitioners to the scoring problem discussed above. The development of a scoring method that provides a wider range of ratings is needed. This would require experimenting with various In-basket scoring methods, using the same set of in-basket protocols.

\section{REFERENCE}

Babbie, E. \& Mouton J. (2001). The practice of social research. Cape Town: Oxford University Press.

Guion, R.M. (2002). Validity and reliability. In S. G. Rogelberg (ed.) Handbook of Research Methods in Industrial Organizational Psychology. Malden, Mssachusetts: Blackwell Publishers.

Schroder, H.M. (2004). The fallacy of using in-basket based measures for the validation of leadership dimensions. South African Journal of Industrial Psychology.

SHL (2000). Competency design: towards an integrated human resource management system. SHL Newsline, March 2000, 7.

Spangenberg, H.H. \& Theron, C.C. (2003). Validation of the high performance leadership competencies as measured by an assessment centre in-basket. South African Journal of Industrial Psychology, 29 (2), 29-38. 